\title{
Initiatives towards a concurrent maintenance process
}

\author{
Kristoffer V. Sigsgaard1, Julie K. Agergaard1, Niels Henrik Mortensen', Kasper B. \\ Hansen $^{1}$, Iman Soleymani ${ }^{1}$, Waqas Khalid ${ }^{1}$ \\ ${ }^{1}$ Technical University of Denmark \\ krvsig@mek.dtu.dk \\ s153075@student.dtu.dk \\ nhmo@mek.dtu.dk \\ kabaha@mek.dtu.dk \\ imsole@mek.dtu.dk \\ wakha@mek.dtu.dk
}

\begin{abstract}
Maintenance is coming more and more into focus and in many areas maintenance costs are becoming increasingly important to running a profitable business. Performing the right maintenance is therefore important to many companies. The right maintenance is a balance of costs, impact on production, reduction of downtime, ensuring high safety and reducing environmental impact. The foundation of performing the right maintenance is an effective maintenance process. A maintenance process, as described in literature, includes identification of required maintenance; planning of the maintenance tasks; scheduling of the planned tasks; execution of the maintenance; and close-out of the maintenance job. Descriptions of the maintenance process in literature mainly follow a sequential process similar to that of sequential engineering. The sequential process is typically slow and inefficient and therefore does not support the need for running an efficient maintenance program. This paper presents a literature review that looks into how product development have met similar problems with a sequential development process and how this problem is solved through concurrent engineering. The maintenance process is analyzed through a literature review looking at different maintenance processes. The literature shows that the maintenance process is subject to large variation depending on the source, but that all the sources base their process on a sequential structure. It is also observed that maintenance is facing similar problems to the sequential product development. Based on the literature review, four initiatives for improving the maintenance process is suggested. The initiatives are based on the identified methodology from concurrent engineering. A case study is used to further understand the sequential issues in maintenance and to highlight how the initiatives can influence the maintenance process. The case study shows that implementing the initiatives gives a potential $12 \%$ cost reduction. This indicates a clear need for a more concurrent maintenance process, but to fully conclude the need and benefits of a concurrent maintenance process, more studies need to be conducted.
\end{abstract}

Keywords: information management, process improvement, design process, knowledge management 


\section{Introduction}

Maintenance is becoming a more and more important cost factor to consider with the increase of mechanization and automation in industry. Doing maintenance disturbs production which reduces productivity and thereby the profitability. However a failure during production will not only affect productivity, but leads to safety and environmental problems that can affect the company image (Alsyouf, 2007). This tradeoff has made maintenance a large subject in research.

In literature, the maintenance process is often considered sequential in nature with stages that are dependent on the previous stage (Al-Turki, 2009; Barberá, Crespo, Viveros, \& Stegmaier, 2012; Deighton, 2016; Haroun \& Duffuaa, 2009; Márquez, 2007). This structure is similar to the sequential engineering process used in product development, where the responsibility for the design passes between the various departments in a stepwise manner. Research has defined this process as slow with a poor yield (Eversheim, Roggatz, Zimmermann, \& Derichs, 1997; Putnik \& Putnik, 2019; Swink, Sandvig, \& Mabert, 1996; Trygg, 1993). Literature has many examples of the benefits of implementing concurrent engineering to alleviate the downsides of sequential engineering (Bhuiyan, Thomson, \& Gerwin, 2006; Pullan, Bhasi, \& Madhu, 2010; Putnik \& Putnik, 2019; Swink et al., 1996).

This paper proposes four initiatives to improve the maintenance management process based on concurrent engineering theory. The initiatives are based on a collection and comparison of literature within sequential and concurrent engineering and maintenance management. The initiatives are then applied in a case study on a maintenance intensive offshore company. Estimates of the possible savings are made based on optimizing historical operations and calculating the cost difference. Therefore this study focuses on:

1. How the maintenance process is similar to the sequential engineering process.

2. How the maintenance process can be improved by utilizing methods from concurrent engineering.

3. How the improvements affect the costs surrounding the maintenance process.

This paper first presents the methods utilized throughout the paper. Next, a review of current literature on sequential and concurrent engineering and maintenance management is presented. Following the literature review, the contribution to the current body of literature is described. Finally, a case study is used to highlight the effects of the suggested initiatives and the findings are discussed.

\section{Research method}

The research in this paper applies the methodology from concurrent engineering literature to help improve a sequential maintenance process. To achieve this, the paper builds on existing literature from sequential and concurrent engineering and maintenance management. The paper then makes use of a case study to further highlight the need and to quantify the benefits of applying the concepts of concurrent engineering in a maintenance process.

The literature review was based on searches in DTU FindIt and Web of Science. The yield of the maintenance literature study is rather limited, with only nine sources directly describing the phases of the maintenance management process. The study was conducted using the following search terms: 
- Plan do check act

- Plan do check act AND maintenance

- Maintenance Management

- Maintenance organization

- Maintenance process

- Management of maintenance systems

- Maintenance workflow

- Maintenance policy

- Maintenance management flow

- Maintenance management process

- Maintenance AND business logic

The case study was conducted in a major oil and gas company with a focus on their Danish production facilities. The focus was on two onshore departments who had separate maintenance processes but maintained the same part of the facilities. The study was carried out as a collaboration between two MSc projects and a $\mathrm{PhD}$ project at the Technical University of Denmark (DTU). To understand the maintenance process, a series of semi-structured interviews and workshops were conducted with managers and engineers from both of the two onshore departments. The information collected was supported by quantitative data from 2012-2018. To quantify the impact of implementing the proposed initiatives, maintenance reports and production and performance data from 2016-2018 was analyzed. The estimated benefit was calculated based on the data collected through reports, workshops and interviews and was verified by experts from the case company.

\section{Literature review}

This literature review highlights research within sequential and concurrent engineering processes, as well as the maintenance management process. The sequential and concurrent engineering section focuses on the differences of the processes and describes the barriers and benefits of implementing concurrent engineering in a company. In the maintenance management section, different sources were grouped into a general process structure. The grouping shows variation in what is included in the maintenance process in different sources, which gives an insight into the uncertainties that characterizes the maintenance management process. The suggested organizational structure that goes along with each maintenance process is also highlighted to enable further comparison to sequential and concurrent engineering.

\subsection{Sequential and concurrent engineering}

Sequential - or traditional - engineering is an engineering development process, where each stage of the process is dependent on the completion of the previous stage. Each stage is carried out separately and at the end of a stage, control and responsibility of the project is handed to the next team. The next stage cannot begin before the previous stage is completed (Putnik \& Putnik, 2019; Swink et al., 1996).

Handing over responsibility and the need for completion makes sequential engineering a slow process: there can be no overlap in work, meaning the time-to-market is the sum of time spent at each stage (Eversheim et al., 1997; Trygg, 1993). As teams from each stage do not directly collaborate, the process will often result in products that are not optimally market-oriented and that are inefficient to manufacture. The design will often also have to be reworked at each stage due to the different challenges faced in the stages (Trygg, 1993). 
A widely accepted method to alleviate the issues from sequential engineering is called concurrent or simultaneous engineering (Bhuiyan et al., 2006; Pullan et al., 2010; Putnik \& Putnik, 2019; Swink et al., 1996). The concurrent engineering process is characterized by teams or team representatives working together on the design from the beginning of the project. This causes all aspects of the lifecycle to be considered from the beginning, resulting in fewer changes later in the process (Putnik \& Putnik, 2019; Swink et al., 1996). Numerus benefits of concurrent engineering are mentioned in literature:

1. Project schedule reduction (Bhuiyan et al., 2006)

2. Shorter defect-free prototype delivery (Bhuiyan et al., 2006)

3. Improved production yield (Bhuiyan et al., 2006; Swink et al., 1996)

4. Time-to-market shortened (Bhuiyan et al., 2006; Swink et al., 1996) by 30-60\% (Pullan et al., 2010)

5. Higher quality products (Swink et al., 1996)

6. Up to $20 \%$ product development costs saved (Swink et al., 1996)

7. $15-50 \%$ reduction in lifecycle costs (Pullan et al., 2010)

8. 55-95\% reduction in engineering changeover requests (Pullan et al., 2010)

As the larger part of a design is determined in the early stages of development (Martin, Dantan, \& Siadat, 2007; McAloone \& Bey, 2009; Saravi, Newnes, \& Mileham, 2013; Shehab \& Abdalla, 2001; Zrim, Maletz, \& Lossack, 2006) it is of interest that the decisions made at these stages are the right decisions. It is also preferable to avoid changes in later stages, as changes are cheaper to make in the early stages of development (Martin et al., 2007).

Bhuiyan et al. (2006) discusses the barriers of implementing concurrent engineering and tools to overcome these barriers. Barriers can be lack of business unit and top management support, difficulty of setting requirements at concept stage, lack of control of project resources, lack of interaction between groups, lack of involvement of key groups at project start, etc. (Bhuiyan et al., 2006). A selection of possible options and tools to overcome these barriers as presented by Bhuiyan et al. (2006) are as follows:

- Set multifunctional teams at project outset

- Define responsibilities clearly

- Dedicate necessary resources

- Define requirements early

- Improve team communication

- Improve interactions between groups

- Increase use of and improve IT tools

The difference in the sequential and concurrent engineering processes lies mainly in the amount of collaboration between departments of different competencies from the outset of a project. To determine how the maintenance management process connects to these processes, the following section presents literature on the subject.

\subsection{Maintenance management process}

A grouping of literature into a standard structure was conducted to determine the maintenance management process flow from end-to-end. The structure covers all of the identified steps from literature. I.e. from identification of work to close out of the job and back to identification. The resulting overarching process steps are shown in figure 1. A more in depth mapping of the process stages as presented in the literature is shown in table 1. In maintenance, the job is first 
identified. The required tasks, resources etc. are then planned. Next, the job is scheduled alongside all the other required maintenance. When it is the scheduled time, the job is executed. Once the job is executed, the resources spent during execution are logged and the job is closed. The steps of the process requires a variety of competencies (Dansk Standard, 2004; Deighton, 2016; Gulati \& Smith, 2008).

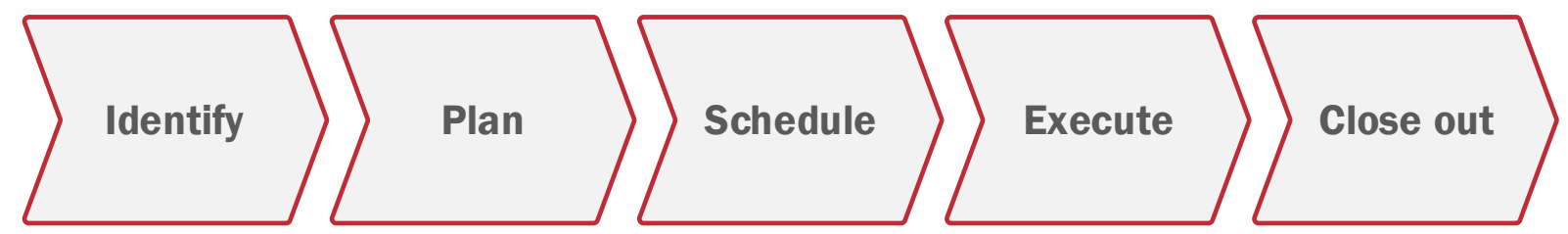

Figure 1: The identified general steps of the maintenance management process flow.

When comparing different maintenance processes from the literature to the five main stages in figure 1, two observations are made. First, it is seen that there is a high variety in the different maintenance processes and second, none of the maintenance processes cover all identified aspects of the five maintenance stages. The comparison is made in table 1 . This variation and lack of literature indicates that the maintenance process is hard to standardize and that there is a need for more research on the overarching process.

Table 1: Overview of the process mentioned in each of the sources. The table displays the five identified stages and the steps mentioned by each source.

\begin{tabular}{|c|c|c|c|c|c|c|c|c|c|c|c|}
\hline & References & $\begin{array}{c}\text { Haroun, } \\
\text { Duffuaa } \\
\text { (2009) }\end{array}$ & $\begin{array}{c}\text { Duffuaa, } \\
\text { Haroun } \\
(2009) \\
\end{array}$ & $\begin{array}{c}\text { Al-Turki } \\
(2009)\end{array}$ & $\begin{array}{c}\text { Dansk } \\
\text { Standard } \\
\text { (2004) }\end{array}$ & $\begin{array}{l}\text { Gulati, } \\
\text { Smith } \\
\text { (2008) }\end{array}$ & $\begin{array}{l}\text { Márquez } \\
\text { (2007) }\end{array}$ & $\begin{array}{l}\text { Deighton } \\
(2016)\end{array}$ & $\begin{array}{c}\text { Barberá } \\
\text { et al. } \\
(2012)\end{array}$ & $\begin{array}{c}\text { Kelly, as } \\
\text { described } \\
\text { in } \\
\text { Sherwin } \\
(2000)\end{array}$ & Sum \\
\hline \multirow{12}{*}{ Identify } & Failure/work requirement detection & & & & $\mathrm{x}$ & & $\mathrm{x}$ & $\mathrm{x}$ & & $\mathrm{x}$ & 4 \\
\hline & Understand equipment dependencies & & & & $\mathrm{x}$ & & & & & & 1 \\
\hline & Determine priority & & & & & $\mathrm{x}$ & $\mathrm{x}$ & $\mathrm{x}$ & & & 3 \\
\hline & Dertermine criticality & & & & & $\mathrm{x}$ & & $\mathrm{x}$ & $\mathrm{x}$ & & 3 \\
\hline & Determine Failure mode & & & & $\mathrm{x}$ & & & & $\mathrm{x}$ & & 2 \\
\hline & Create maintenance request & & & & & $\mathrm{x}$ & $\mathrm{x}$ & $\mathrm{x}$ & & & 3 \\
\hline & $\begin{array}{l}\text { Evaluate current maintenance performance/impact } \\
\text { and improve }\end{array}$ & $\mathrm{x}$ & $\mathrm{x}$ & $\mathrm{x}$ & $\mathrm{x}$ & & $\mathrm{x}$ & & $\mathrm{x}$ & $\mathrm{x}$ & 7 \\
\hline & Setting performance objectives & $\mathrm{x}$ & $\mathrm{x}$ & $\mathrm{x}$ & $\mathrm{x}$ & & & & $\mathrm{x}$ & $\mathrm{x}$ & 6 \\
\hline & How to achieve performance objectives & $\mathrm{x}$ & $\mathrm{x}$ & & & & & & & $\mathrm{x}$ & 3 \\
\hline & Quantify objectives & & & $\mathrm{x}$ & & & & & $\mathrm{x}$ & $\mathrm{x}$ & 3 \\
\hline & Determine consequence of failure & & & & & & & & $\mathrm{x}$ & & 1 \\
\hline & $\begin{array}{l}\text { Determine inspection requirements for critical } \\
\text { equipment }\end{array}$ & & & & & & & & $\mathrm{x}$ & & 1 \\
\hline \multirow{10}{*}{ Plan } & Understand maintenance request/requirements & & & $\mathrm{x}$ & $\mathrm{x}$ & $\mathrm{x}$ & $\mathrm{x}$ & $\mathrm{x}$ & & $\mathrm{x}$ & 6 \\
\hline & Set required tasks & $\mathrm{x}$ & $\mathrm{x}$ & $\mathrm{x}$ & $\mathrm{x}$ & $\mathrm{x}$ & $\mathrm{x}$ & $\mathrm{x}$ & $\mathrm{x}$ & & 8 \\
\hline & Plan material and resource usage & $\mathrm{x}$ & $\mathrm{x}$ & & $\mathrm{x}$ & $\mathrm{x}$ & $\mathrm{x}$ & & $\mathrm{x}$ & & 6 \\
\hline & Estimate required work hours & & & & $\mathrm{x}$ & $\mathrm{x}$ & & & & & 2 \\
\hline & Determine task frequency (CM always only once) & & & & & & $\mathrm{x}$ & & & & 1 \\
\hline & Formulate long text & & & & $\mathrm{x}$ & $\mathrm{x}$ & $x$ & & & & 3 \\
\hline & Identify long delivery items & & & & & $x$ & & & & & 1 \\
\hline & Relevant procedures (safety, regulatory etc.) & & & & & & $\mathrm{x}$ & $\mathrm{x}$ & & & 2 \\
\hline & Maintenance location (on site, repair shop etc.) & & & & & & $\mathrm{x}$ & & & & 1 \\
\hline & $\begin{array}{l}\text { Coordinate with purchasing personnel on required } \\
\text { materials }\end{array}$ & & & & & $\mathrm{x}$ & & $\mathrm{x}$ & & $\mathrm{x}$ & 3 \\
\hline \multirow{3}{*}{ Schedule } & Schedule planned maintenance & $\mathrm{x}$ & & $\mathrm{x}$ & & $\mathrm{x}$ & $\mathrm{x}$ & $\mathrm{x}$ & $\mathrm{x}$ & $x$ & 7 \\
\hline & Ensuring optimal crew utilization & & & & & $\mathrm{x}$ & & & $\mathrm{x}$ & $\mathrm{x}$ & 3 \\
\hline & Resource management & & & & & $\mathrm{x}$ & $\mathrm{x}$ & & $\mathrm{x}$ & $\mathrm{x}$ & 4 \\
\hline \multirow{5}{*}{ Execute } & Assigning specific personnel & & & & $\mathrm{x}$ & $\mathrm{x}$ & $\mathrm{x}$ & $\mathrm{x}$ & & & 4 \\
\hline & Collect resources/tools & & & & $\mathrm{x}$ & & $\mathrm{x}$ & $\mathrm{x}$ & & & 3 \\
\hline & Execute planned tasks & $\mathrm{x}$ & $\mathrm{x}$ & $\mathrm{x}$ & $\mathrm{x}$ & $\mathrm{x}$ & $\mathrm{x}$ & $\mathrm{x}$ & & & 7 \\
\hline & Travel to worksite & & & & & & $\mathrm{x}$ & & & & 1 \\
\hline & Prep/clearing of worksite & & & & & & $\mathrm{x}$ & $\mathrm{x}$ & & & 2 \\
\hline \multirow{6}{*}{ Close out } & Observation and measurement recording & & & & $\mathrm{x}$ & $\mathrm{x}$ & $\mathrm{x}$ & & & $\mathrm{x}$ & 4 \\
\hline & Job reporting & & & & $\mathrm{x}$ & $\mathrm{x}$ & $\mathrm{x}$ & $\mathrm{x}$ & $\mathrm{x}$ & & 5 \\
\hline & Update master data & & & & & & & $\mathrm{x}$ & $\mathrm{x}$ & & 2 \\
\hline & Order closure & & & & & & & $\mathrm{x}$ & & & 1 \\
\hline & Quality assurance/check & & & & & & & $\mathrm{x}$ & $\mathrm{x}$ & $\mathrm{x}$ & 3 \\
\hline & Review/update of reused plans & & & & & & & $\mathrm{x}$ & & $\mathrm{x}$ & 2 \\
\hline & 36 & 7 & 6 & 7 & 15 & 17 & 20 & 18 & 15 & 13 & \\
\hline
\end{tabular}


The overview in table 5 shows that four of the nine sources have all five maintenance steps in their process. Scheduling and close out are the two steps missing in three of the sources. Scheduling is only relevant when looking at multiple maintenance task at the same time and the documentation in close out is the basis for processes that include continuous improvements. This is why scheduling and close out is left out by Duffuaa and Haroun (2009) and close out was left out by Haroun and Duffuaa (2009) and Al-Turki (2009). Kelly (Sherwin, 2000) and (Barberá et al., 2012) have left out the execution phase, as these processes are focused on the role of management and execution is performed by onsite maintenance personnel.

All the references in table 1 consider the process in a step wise manner. The following describes how each source considers roles and collaboration across the stages. Barberá et al. (2012), Kelly (Sherwin, 2000), and Deighton (2016) mention that each step must be completed before the next.

According to Haroun and Duffuaa (2009), the steps are separate and a maintenance manager has influence on all of them. The amount of influence depends on the organizational model. This can be a centralized model where all staff reports to the same central maintenance manager, or a decentralized model, where staff reports to operations or area managers who then report to the top management. A hybrid structure of the two models can take two shapes: the staff reports to both a central manager and an operational or area manager; or the staff reports to an operational or area manager until the capacity of the area is exceeded. The staff will in that case report to a central manager.

Duffuaa and Haroun (2009) suggest a control process that can be utilized by the control manager described by Haroun and Duffuaa (2009), but does not further discuss roles and collaboration. Al-Turki (2009) writes, that planning and scheduling are the key components of successful maintenance, and that planning of maintenance work is a prerequisite of sound scheduling.

Márquez (2007) mentions that the 'silo' style approach to maintenance management would play a pivotal role when including all of the highlighted steps in table 1. 'Silo' meaning that each department work independently of each other.

Gulati and Smith (2008) mention, as the only one of the sources, how personnel should collaborate across all the stages of the process. Especially planning and scheduling are dependent on each for the maintenance efforts to be successful. Stages are however still considered separate, and responsibilities for each stage lies within different departments.

\section{Contribution}

Literature provides numerus examples of the benefits of concurrent engineering over sequential engineering: shorter time-to-market, higher quality products, improved production yield and so forth. The literature on maintenance management shows how the maintenance management process often follows a sequential engineering process. This is seen in how different departments are responsible for different stages and that the start of the next stage is dependent on the completion of the previous. Especially two of the sources mention how sound scheduling is dependent on good maintenance planning. Only one in nine sources mentions collaboration across the stages of the process as a necessity, however responsibility is still kept within different departments. As mentioned in literature, having a sequential structure can lead to inefficient communication back and forth and changes having to be made at the start of each stage. This leads to set backs in the progress of the job (figure 2). 


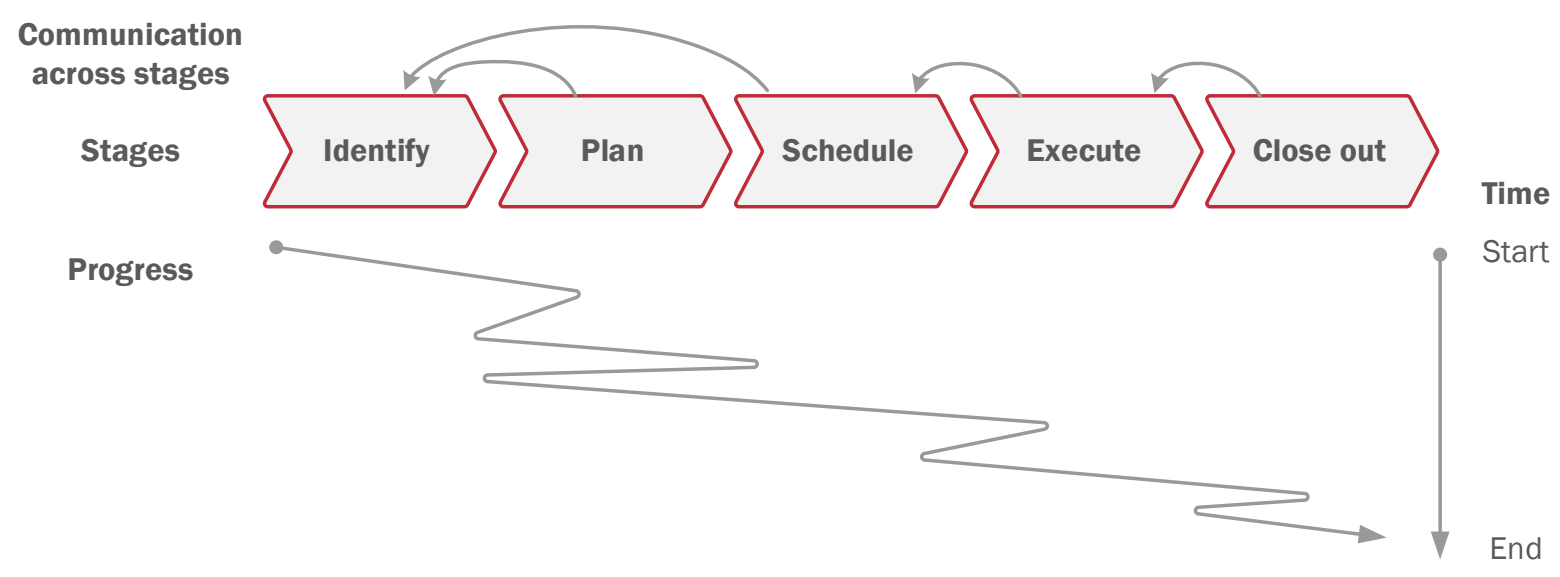

Figure 2: The current maintenance process. Changes made at the beginning of each stages sets back the progress of the job. Communication across stages is jumbled and inefficient. Time from start to end is longer due to the setbacks

Since there are a number of similarities between the maintenance management process and the sequential engineering process, applying concurrent engineering tools to the maintenance management process can help improve the process. Four initiatives are suggested, that can move maintenance management towards a concurrent engineering type of process:

- Determining what decisions are necessary at what time

- Alignment of stages

- Having the right people present at the right times

- Procuring the right data

The initiatives are based on the recommendations made by Bhuiyan et al. (2006) as highlighted in section 3.1. When it has been determined what decisions are needed at what time, the process can be aligned. This entails ensuring that decisions that correlate are taken at the same time to avoid discrepancies that have to be changed later in the process. Knowing the requirements also allows easier planning of multifunctional teams and more accurately dedicating the required resources at the stages as mentioned by Bhuiyan et al. (2006). When the full requirements for the process are mapped out, it is easier to plan what data is required for the decisions being made throughout. Together, these four initiatives increase control over the process and help ensure that the necessary knowledge is always available. The initiatives streamline the communication and ensures that the job progress is continuously moving forward. Having fewer setbacks throughout the project enables a shorter time from start to end (figure 3), just as with concurrent engineering (Bhuiyan et al., 2006; Pullan et al., 2010; Swink et al., 1996). 


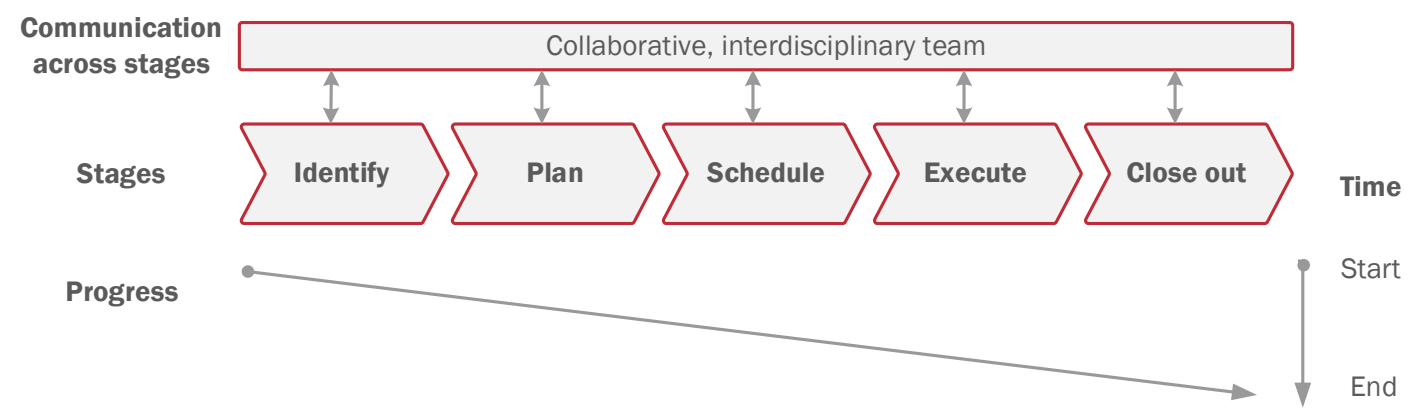

Figure 3: Implementing the four concurrent initiatives in the maintenance process. Job progression is continuous and communication across the stages is clear and controlled. Time from start to end is shorter.

\section{Case study}

The case study described in this section was used to further investigate the possible benefits of employing the suggested concurrent engineering initiatives in maintenance management. The study was conducted in a company that operates offshore oil and gas platforms with a focus on the expensive offshore maintenance operations. As some of the maintenance requires an extra rig to be transported to the field, the schedule is required to be created up to two years in advance. This means that scheduling is performed before planning, switching around the scheduling and planning stages compared to the structure identified in literature. The maintenance process stages are shown in figure 4.

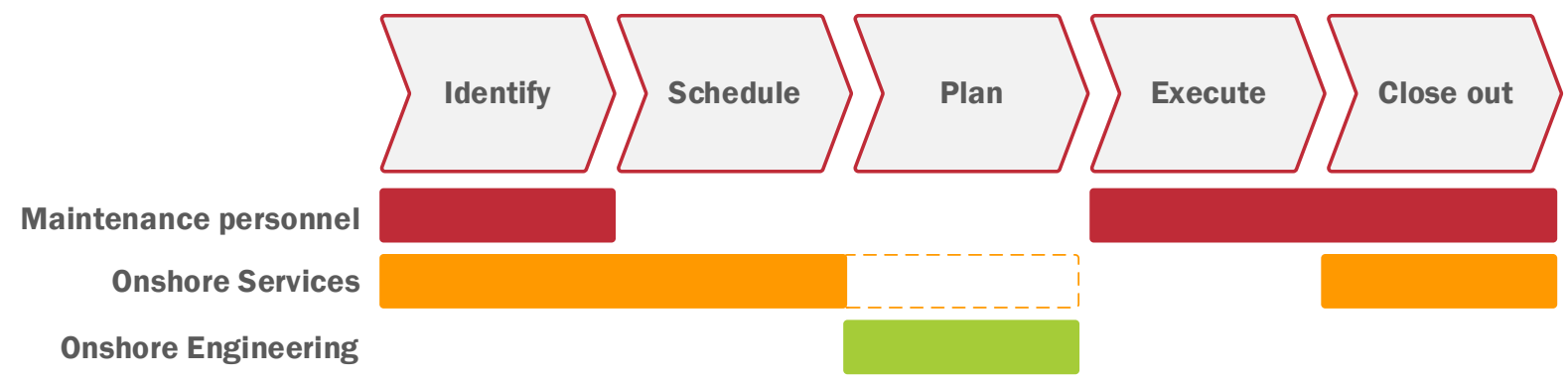

Figure 4: The maintenance process stages utilized at the case company. The planning stage is not a part of the Onshore Services scope, but they are often required to help Onshore Engineering in this stage.

Different departments in the organization have responsibility of each of the stages; some offshore some onshore. Identification is performed either by offshore personnel discovering an error or by onshore personnel from the Onshore Services department based on data or legislative requirements. Scheduling is done by Onshore Services. Scheduling consists of accepting the work request and placing it within the rig or platform schedules. Planning is done by another onshore department called Onshore Engineering. During this stage, the details of the operations are determined based on the data collected at the identification stage. If data is missing, the onshore engineer must collect the data or discuss the state of the equipment with experts from Onshore Services. This is indicated in figure 4 by the dashed box for Onshore Services in the planning stage. The execution is either performed by platform personnel or by rig personnel. It is cheaper if the operations can be performed from the platform, as there are a lot of extra costs associated with rig operations. However, rig operations are faster and some operations cannot be performed from the platform, as the equipment is too large. Close out is performed by the offshore personnel filling out information about the job and onshore personnel who closes out the finances and other administrative tasks. 
The case company has expressed a desire to improve the efficiency of the process, as inefficient maintenance leads to unnecessary extra costs and production loss. Through workshops and semi-structured interviews the problems that needed solving were identified: when the schedule is made, Onshore Services needs to know whether a rig is required or not. Often it can be hard to tell without knowing the details of the operations. As the details are not determined until three months before the execution, Onshore Services makes an estimation of the requirements. An estimation can be difficult to make as there are several factors that play into the tradeoff. This uncertainty might result in the scheduling of a rig even though it is not required, as Onshore Services must ensure that the required resources are available. The onshore engineer determining the operations also has problems with planning within the three-month window. Often the required data is not available and some data cannot be collected within that short a window. The onshore engineer also often has to go back to Onshore Services to determine some of the operations. This takes time from the tasks that are planned for Onshore Services, slowing down the work.

In a workshop with representatives from both Onshore Services and Onshore Engineering, a solution to the identified problems was worked out. It was decided that both Onshore Engineering and Onshore Services should be included in the process from the approval of the job until the operations are fully detailed. This would let the onshore engineer ensure that the correct data is collected before planning commences. The onshore engineer would also be able to provide expertise when determining whether a rig is needed or not. This would result in the extra costs for the rig only being applied when the rig resources are truly required. The new process configuration is shown in figure 5.

The identified solution aligns the process, ensuring that connected decisions are being made at the same time and that these decisions are all made with the right people present. This is achieved by having both Onshore Services and Onshore Engineering present in scheduling and planning. By mapping out the process, it is possible to determine what decisions are being made at what stage and what data is required for it. Having a clear focus in each of the individual stages shortens them and makes it easier to ensure that the right knowledge is available at the start of a stage.

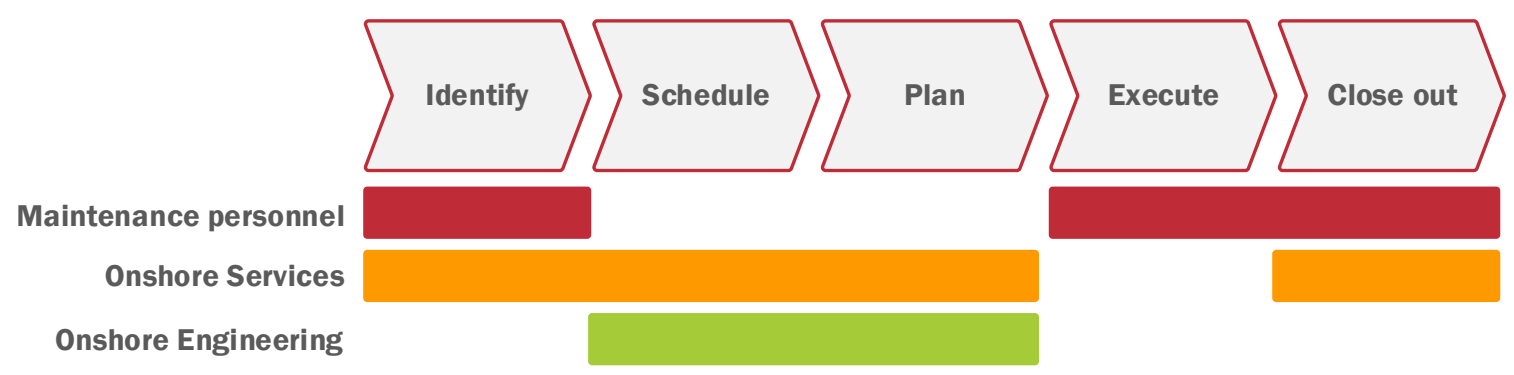

Figure 5: The suggested maintenance management process. Onshore Engineering and Onshore Services cooperate to ensure optimal scheduling and planning.

The effects of implementing a process like the one above can be difficult to quantify, as the changes made have long term effects. Instead, historical data of the operations from 2016-2018 was used to determine how much could have been saved if the right decisions had been made during scheduling and the right data had been available in planning. For each of the maintenance jobs from 2016-2018 the cost saving potential from the suggested change was identified. The potential cost savings from all of the jobs was then added up to a total saving of $12 \%$ on the maintenance costs in those years. 


\section{Discussion}

The case company highlights an implementation of concurrent engineering tools into a sequential engineering process structure. The company follows a process close to that described in literature, except scheduling comes before planning due to the constraints of the rig. It also resembles the structure of sequential engineering, in how each stage has a different responsible department.

From the case company it is seen that communication across the departments and stages is required, but that it is outside of the resources set aside for the process. For the personnel this means extra tasks outside of their given work scope. Making changes late in the process is also difficult in the case company, as the scheduling of a rig must be done up to two years in advance. These issues have caused the maintenance process in the case company to be costly, inefficient and results in unnecessary production loss. The extra costs especially come from rigs being deployed even though they are not needed.

Some of the barriers of implementing concurrent engineering were also seen in the case company. The largest barrier was that it was hard to define whether maintenance required a rig or not during scheduling, as knowledge about the actual job was missing. This happened, as all key groups were not present at the outset. The onshore engineer would often also be missing the resources required for planning and would have to disturb Onshore Services to collect them. The solution identified in collaboration with stakeholders from the company utilizes the initiatives for overcoming concurrent engineering barriers described in section 4. Having both Onshore Services and Onshore Engineering working on scheduling means that multifunctional teams are utilized from the beginning of the process. Having the multifunctional team allows proper requirements to be set from the beginning of the process when determining whether to book a rig or the platform personnel. Having both departments responsible for scheduling and planning signifies the stake both departments have in making sure both stages are successful. This means that both stages are a part of the work scope in the departments, making the required work a part of the resources allocated to the departments. Having the onshore engineer present at scheduling also gives rise to identifying the required data at an earlier stage. This gives Onshore Services more time to collect the required data before detailed operations planning commences. The shared responsibility also facilitates more communication and interaction between the two groups.

As shown through estimations based on the historical data, the initiatives can have a positive effect on the maintenance process.

\section{Conclusion}

This paper maps out the sequential and concurrent engineering process alongside the maintenance process and suggests initiatives for improving the maintenance process based on the concurrent process. The current body of literature on the overarching maintenance processes has a large variation in the steps required for each stage of the process. Nevertheless, the different maintenance processes are all based on a sequential process, as the previous step has to be completed before the next can start. This is similar to the sequential engineering process, which in literature is shown to be slow with a lower quality yield. In product development, these problems are solved by implementing a concurrent engineering process.

In the case study, a sequential maintenance process was analyzed in which the issues identified in literature were also apparent. Through the case study it is shown that applying the suggested initiatives enables better decision making throughout the maintenance process. The case study shows, that by making sure the right decision is taken at the right time, it is possible to reduce the maintenance costs by $12 \%$. 
This conclusion is based on a single case study and is therefore only an indicator at the potential of the suggested initiatives. Further and longer term studies on the effects of the initiatives should be conducted in order to fully understand the extent of the benefits. Studies on other initiatives such as team communication and IT tool improvements could also benefit this research area.

\section{References}

Al-Turki, U. M. (2009). Maintenance Planning and Scheduling. In Handbook of Maintenance Management and Engineering (pp. 237-261). Springer.

Alsyouf, I. (2007). The role of maintenance in improving companies' productivity and profitability. International Journal of Production Economics, 105(1), 70-78. https://doi.org/10.1016/j.ijpe.2004.06.057

Barberá, L., Crespo, A., Viveros, P., \& Stegmaier, R. (2012). Advanced model for maintenance management in a continuous improvement cycle: Integration into the business strategy. International Journal of Systems Assurance Engineering and Management, 3(1), 47-63. https://doi.org/10.1007/s13198-012-0092-y

Bhuiyan, N., Thomson, V., \& Gerwin, D. (2006). Implementing concurrent engineering. Research Technology Management, 49(1), 38-43. https://doi.org/10.1080/08956308.2006.11657357

Dansk Standard. (2004). Dependability management - Part 3-14: Application guide Maintainance and maintenance support.

Deighton, M. G. (2016). Maintenance Management. In Facility Integrity Management (pp. 87139). Elsevier.

Duffuaa, S. O., \& Haroun, A. E. (2009). Maintenance Control. In Handbook of Maintenance Management and Engineering (pp. 93-112). Springer.

Eversheim, W., Roggatz, A., Zimmermann, H. J., \& Derichs, T. (1997). Information management for concurrent engineering. European Journal of Operational Research, 100(2), 253-265. https://doi.org/10.1016/S0377-2217(96)00288-3

Gulati, R., \& Smith, R. (2008). Work Management: Planning and Scheduling. In Maintenance and reliability best practices (pp. 71-97).

Haroun, A. E., \& Duffuaa, S. O. (2009). Maintenance Organization. In Handbook of Maintenance Management and Engineering (pp. 3-15). https://doi.org/10.1007/978-184882-472-0 1

Márquez, A. C. (2007). Maintenance Management Characterization: Process, Framework and Supporting Pillars. In The Maintenance Management Framework (pp. 11-38). Springer.

Martin, P., Dantan, J.-Y., \& Siadat, A. (2007). Cost Estimation and Conceptual Process Planning. Digital Enterprise Technology, 243-250. https://doi.org/10.1007/978-0-38749864-5_28

McAloone, T. C., \& Bey, N. (2009). Environmental improvement through product development - A guide. Retrieved from www.ecodesign.dtu.dk

Pullan, T. T., Bhasi, M., \& Madhu, G. (2010). Application of concurrent engineering in manufacturing industry. International Journal of Computer Integrated Manufacturing, 23(5), 425-440. https://doi.org/10.1080/09511921003643152

Putnik, G. D., \& Putnik, Z. (2019). Defining Sequential Engineering (SeqE), Simultaneous engineering (SE), Concurrent Engineering (CE) and Collaborative Engineering (ColE): On similarities and differences. Procedia CIRP, 84, 68-75. https://doi.org/10.1016/j.procir.2019.07.005

Saravi, M., Newnes, L., \& Mileham, T. (2013). Optimising Performance and Cost at the Early Design Stages. 3(3), 214-228. 
Shehab, E. M., \& Abdalla, H. S. (2001). Manufacturing cost modelling for concurrent product development. Robotics and Computer-Integrated Manufacturing, 17(4), 341-353. https://doi.org/10.1016/S0736-5845(01)00009-6

Sherwin, D. (2000). A review of overall models for maintenance management. Journal of Quality in Maintenance Engineering, 6(3), 155-157. https://doi.org/10.1108/13552510010341171

Swink, M. L., Sandvig, C., \& Mabert, V. A. (1996). Customizing concurrent engineering process five case studies.pdf.

Trygg, L. (1993). Concurrent engineering practices in selected Swedish companies: A movement or an activity of the few? The Journal of Product Innovation Management, 10(5), 403-415. https://doi.org/10.1016/0737-6782(93)90098-B

Zrim, G., Maletz, M., \& Lossack, R. (2006). Experience based cost management in the early stages of product development. 9th International Design Conference, DESIGN 2006, $1569-1574$. 